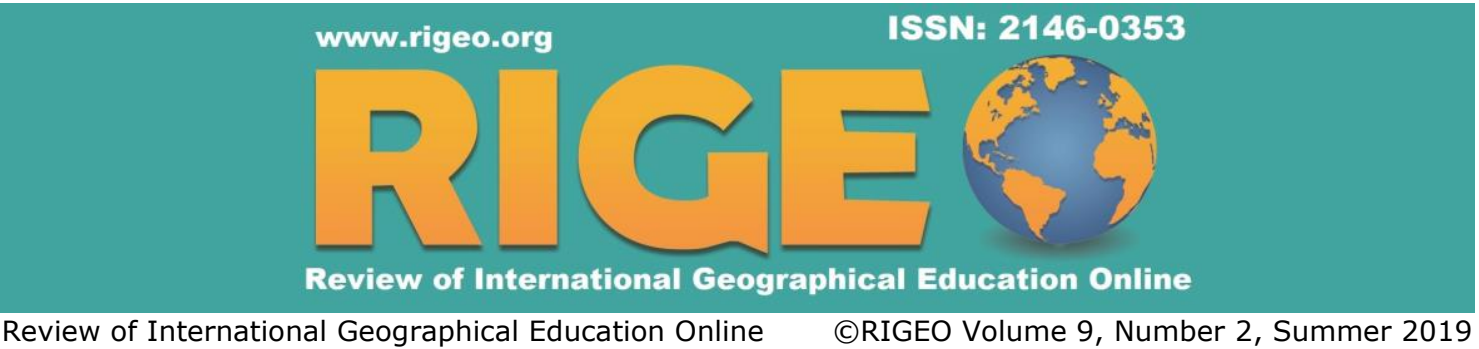

Research Article

Copyright @ RIGEO 2019

To cite this article: Namlı Altıntaş, İ., Karaaslan, H. (2019). Peer assessment and active learning experiences of social studies teacher candidates. Review of International Geographical Education Online (RIGEO), 9(2), 319-345. Retrieved from http://www.rigeo.org/vol9no2/Number2Summer/RIGEO-V9-N2-4.pdf

DOI: $10.33403 /$ rigeo.615716

Submitted: November 26, $2018 \quad$ Revised: January 22, $2019 \quad$ Accepted: May 30, 2019

\title{
Peer Assessment and Active Learning Experiences of Social Studies Teacher Candidates
}

\author{
İrem NAMLI ALTINTAŞ 1 \\ Suleyman Demirel University, Isparta, TURKEY \\ Hüseyin KARAASLAN² \\ Suleyman Demirel University, Isparta, TURKEY
}

\begin{abstract}
The aim of this study is to determine the opinions of teacher candidates on how teacher efficiency should be through peer assessment and active learning. For this purpose, an implementation was performed on the presentation skills of the social studies teacher candidates at a state university. In the study group, there are 28 teacher candidates as 10 males and 18 females. The study was designed in the case study. For 9 weeks, 8 groups gave lessons and a general assessment was performed for 1 week. The teacher candidates, in groups of twos, made presentations in accordance with the class level related to the subjects included in the secondary school social studies program. The presentations are based on critical, empathetic, reflective and project-based thinking. As the data collection tool, preliminary and final assessment forms consisting of open-ended questions were distributed. During the process, the teacher candidates were asked to keep individual and group reflective diaries. The diaries were used to support the final assessment forms. The data were coded through content analysis and analyzed by using the NVIVO 12 program. The main theme in the findings obtained was coded in accordance with peer assessment and active learning. The main themes were determined as The Effect on Peer Relationships, The Effect of Being Assessed, The Effect on the Assessor, and The Effect of the Process. The Category, Code and Dimensions were also shaped according to the main themes. The findings of the reflective diaries support the final assessment. At the end of the process, teacher candidates stated that peer assessment made a positive contribution to them, their relationships with their peers were negatively affected sometimes and active learning contributed to their personal development, professional knowledge, and collaborative works.

Keywords
\end{abstract}

${ }^{1}$ Corresponding author: Assistant Professor, Suleyman Demirel University, Faculty of Education, Department of Social Studies Education, Isparta, Turkey, iremaltintas[at]sdu.edu.tr, ORCID: 0000-0002-3398-5366

${ }^{2}$ Research Assistant, Suleyman Demirel University, Faculty of Education, Department of Social Studies Education, Isparta, Turkey, huseyinkaraaslan[at]sdu.edu.tr, ORCID: 0000-0002-1271-6298

(C) Review of International Geographical Education Online RIGEO 2019 ISSN: 2146-0353 
Active Learning; Peer Assessment; Social Studies Teacher Candidates

While discussing the qualifications that teacher candidates should have, the functions of the faculties of education, which provide them with cognitive, affective and behavioral qualifications, come to mind. For example, it is stated that teachers should have general culture and personal characteristics such as being democratic and tolerant. Having critical thinking ability, being open-minded, having subject matter knowledge and providing independent personality to students are among the other professional qualifications that a teacher should have (Yetim \& Göktaş, 2004).

Teachers of the 21 st century are undoubtedly expected to follow the developments in the world in the field of education and to have adequate knowledge of science and technology. Wagner (2008) listed the 21st-century skills like critical thinking, problemsolving, cooperation, leadership, agility and harmony, entrepreneurship, effective oral and written communication, curiosity, imagination, access to information and analysis. These characteristics that a teacher should have show parallelism with the definition of an effective teacher. Wollfolk classified the definition of an effective teacher as being knowledgeable, clear and enthusiastic. According to Wollfolk's step of knowledge, effective teachers should know the concepts, facts, principles, and processes in their fields and have the ability to practice them. According to the step of being clear, an effective teacher should teach the lesson according to the process steps and avoid vague expressions that are open to interpretation. In the step of being enthusiastic, it is very important for a teacher to be willing in his work (cited by Pehlivan, 2008).

Arender's definition of an effective teacher is discussed in 4 dimensions. These are knowledge-based, repertoire, problem-solving and lifelong learning. According to Arenders, having scientific thinking skills constitutes the knowledge-based dimension while having knowledge of different methods and techniques constitutes the repertoire dimension. In the dimension of problem-solving, the teacher's professional experience can be helpful in the solution of the problem in a different process. Finally, in the dimension of lifelong learning, an effective teacher accepts learning as a process (cited by Pehlivan, 2008).

The behaviors of an effective teacher show parallelism with the student-centered implementations that will activate the student in the classroom. The tasks such as guiding students, making suggestions, giving ideas and leading them are among the responsibilities that the teacher will undertake in the active learning process (Açıkgöz, 2007).

In recent years, there has been an increasing interest in peer assessment which is defined as the evaluation of the value and quality of the products belonging to the peers by the students. (Topping, 2009). Peer assessment is not only a method of assessment but also a process that provides individuals with various skills in the course of time (Somervell, 1993). Özan and Yurdabakan (2008) argued that peer assessment developed the communication skills of students while Biri (2008) put forward that peer assessment increased students' self-confidence and motivation levels. 
In this study, the active learning process undergone by the social studies teacher candidates as a personal experience as well as reflecting it on their professional knowledge were examined through the peer assessment process.

\section{The Purpose of the Study}

In this study, active learning was used in order for the teacher candidates to be able to direct a lesson from the beginning to the end and to deal with the problems that may occur during the lesson. The purpose of this study is to examine teacher candidates' attitudes towards peer assessment and their opinions about using active learning in their lessons.

In line with this purpose, the answers to the following questions were tried to be found:

- How did peer assessments affect the peer relationships of teacher candidates?

- How did the peer assessment process affect the teacher candidates' attitudes towards assessment?

- How did the active learning process affect the professional knowledge of teacher candidates?

- How did active learning experiences affect the personal development of teacher candidates?

- Was effective learning gained as a result of active learning?

\section{The Importance of the Study}

In addition to increasing the cognitive levels of the teacher candidates in the faculties of education and ensuring their professional competences are possible by providing both theoretical and practical knowledge. From this point of view, the method of practice is important for teachers in terms of learning cognitive activities that they will use throughout their professional lives, gaining knowledge and skills such as class management, measurement-assessment, and communication as well as the methods to be used for conveying their knowledge to their students. It can be stated that it is important to develop methods in teacher education based on the relationships between learning types and learning styles of individuals (Demir, 2006). While developing methods, the metacognitive skills of individuals have also become important. One of them is critical thinking. Korkmaz (2009) concluded that the critical thinking skills of the faculty of education students were low and the students studying at Social Studies Teaching program had the lowest scores based on the comparison made in his study. Similarly, Can and Kaymakçı (2015) and Yaman and Yalçın (2004) concluded that the critical thinking skills of teacher candidates were not sufficient. Kalem and Fer (2003) suggested that the students of the faculty of education gained more knowledge through active learning methods.

The studies conducted indicate that peer assessment is also used in the active learning process (Kösterelioğlu, Bayar \& Kösterelioğlu, 2014; Özdemir \& Erdem, 2017). Furthermore, it is stated that peer assessment is effective in terms of providing 
students with skills such as realizing their own learning and gaining a critical perspective (Kılıç, 2016).

This study is important in terms of guiding researchers regarding how active learning can be qualitatively assessed in teacher candidates through continuous participation in the class and peer assessment.

\section{Methodology}

\section{The Method of the Study}

Since this study aims to examine the peer assessment and active learning experiences of social sciences teacher candidates, it was conducted in the case study design. The case study can be used to confirm the accuracy of the theory in obtaining detailed information about an existing situation (Akar, 2018). In this study, a case study was conducted since the effect of active learning on learning would be examined from various perspectives.

\section{Study Group}

This study was carried out with 10 male and 18 female third-class students studying Social Studies Teaching in the 2017-2018 Academic Year. The study group is at the lower-middle economic level.

\section{Data Collection Tools}

Multiple data collection tools can be developed and used in case studies (Creswell, 2007). More than one data collection tool was used in this study.

Assessment Forms. Two assessment forms were used before and after the implementations (Pre-Assessment Form) (Final Assessment Form). In the preassessment form, there are eight open-ended questions asking the teachers to answer their expectations regarding the peer assessment period; in the final assessment form, there are eight open-ended questions asking them to specify their opinions regarding the peer assessment process experienced by them. The reason for using two forms is to check whether there is a difference between the participants' opinions before and after the implementation. For this purpose, the participants were asked to write the last five digits of their formal ID numbers on the forms. The questions were asked as openended.

Reflective Diaries. During the lessons, the participants kept a reflective diary about their friends who were expressing their thinking skills and friends who were teaching lessons in the role of teachers. In the dairy, they expressed their criticism about the lesson taught. These diaries were evaluated by the researcher and an observer after the lesson. In addition, the groups also kept a group diary explaining and assessing the process in which they prepared for the lessons and taught them.

In this study, the reflective diaries were kept related to the lessons and they were used as an auxiliary document to support the assessment forms. 


\section{Implementation of the Study}

In this study, firstly, the existing situation was examined and open-ended questionnaires consisting of questions about peer assessment were distributed to teacher candidates for pre-assessment. Moreover, the diaries that the students kept as individuals and groups were designed to describe the classroom environment, friends and themselves.

The study lasted for 9 weeks. For 9 weeks, 8 groups gave lessons and the general assessment lasted for 1 week. The students, in the group of twos, taught the lesson subjects in the secondary school social studies program in accordance with the class level based on the critical thinking, empathetic thinking, reflective thinking, and projectbased thinking.

Before the implementations, the groups consisting of at least 3 and at most 5 individuals were randomly determined. The reason for determining the groups randomly was to learn whether they could perform peer assessment together with group work.

One person in the group kept a reflective diary describing his experiences, one person explained the way of thinking (e.g. critical thinking or empathic thinking) in his group to the class through direct instruction, and one person assumed the role of the teacher and presented the subject to his friends.

Before the lesson, the teacher candidates presented their lesson plans they prepared to the researcher. Thus, the assessment questions were created by the researcher. An effort was shown to create a real classroom environment during the lesson. Problems or positive situations that could emerge in a classroom environment were tried to be observed in a real classroom environment. Therefore, process-oriented learning was targeted. At the end of the lesson, a performance assessment was conducted with the researcher. In addition, the assessed group was interviewed about what they paid attention to. The researchers did not intervene in the assessments.

The reflective diaries were assessed by the researcher and an observer at the end of the class.

\section{Data Analysis}

The content analysis method was used for data analysis. Content analysis is used to identify words, concepts, themes, phrases, characters, or sentences within one or more texts (K1ziltepe, 2018). Patton (1999) argues that the progress of the content analysis depends on the researcher. The determined theme, category, code, etc. vary depending on the researcher, the subject of the study and the group studied. As a result of the analysis, themes, categories, codes, and dimensions were reached. The data were analyzed by using the NVIVO 12 program.

In this study, the structured assessment forms and reflective diaries were analyzed through content analysis. The assessment forms and reflective diaries were read by the researcher and the observer and coded according to the problem status of the study. The codes were then rearranged according to the main themes. The themes in the study were 
determined as The Effect on Peer Relationships, The Effect of Being Assessed, The Effect on the Assessor and The Effect of Active Learning Process. Based on the analysis of pre-assessment and final assessment forms, each theme was divided into two categories as Pre-Assessment and Final Assessment.

\section{Validity}

Internal Validity. In this study, the internal validity-related forms of Miles \& Huberman (1994) were used to increase internal validity. For this purpose, whether the findings were significant, whether they were credible for the readers and the study group, whether they were detailed or not and the comparison between the compatibility and integrity of the findings and the different data sources were examined. All of these were confirmed by the researchers and experts.

External Validity. The transferability of the results to other situations was checked.

\section{Reliability}

In order to increase the reliability of this study, another researcher specialized in the subject, except the main researcher, who attended the lesson observation. The criterion for this subject is synchronicity. The observer's notes were compared with the researcher's notes during data collection.

With relation to reliability, Miles and Huberman (1994) brought forward issues such as synchronicity, conducting coding controls, whether peer or colleague feedback forms were given or not. In this study, the coding was performed simultaneously. The coding in the assessment forms was checked by two experts in the field of social studies education. In this stage, the reliability formula of Miles and Huberman (1994) was used: Percentage of Consensus $(\%)=[\mathrm{Na}$ (Agreement) $] / \mathrm{Na}$ (Agreement) $+\mathrm{Nd}$ (Disagreement) $x$ 100. The coding of the experts and the researcher were compared and the conformity between the coding was found to be $75 \%$.

\section{Findings}

In this section, the findings related to the changes observed in the participants as a result of the peer assessment and active learning process will be presented. The preassessment and final assessment forms were analyzed by content analysis, themes titled "The Effect on Peer Relationships, The Effect of Being Assessed, and The Effect on the Assessor and The Effect of the Process" and the themes were divided into separate dimensions for the answers given in the pre-assessment and final assessment. The data were comparatively analyzed by being visualized, examples were given to the participant expressions covered by the category, code, and dimensions with direct citations. In addition, the individual and group diaries supporting the expressions in the final assessment forms were analyzed and added to the findings with citations.

\section{The Effect on Peer Relationships}

In this section, before the assessment and assessment experiences, the participants were asked questions about how the peer relationships will change the process and at 


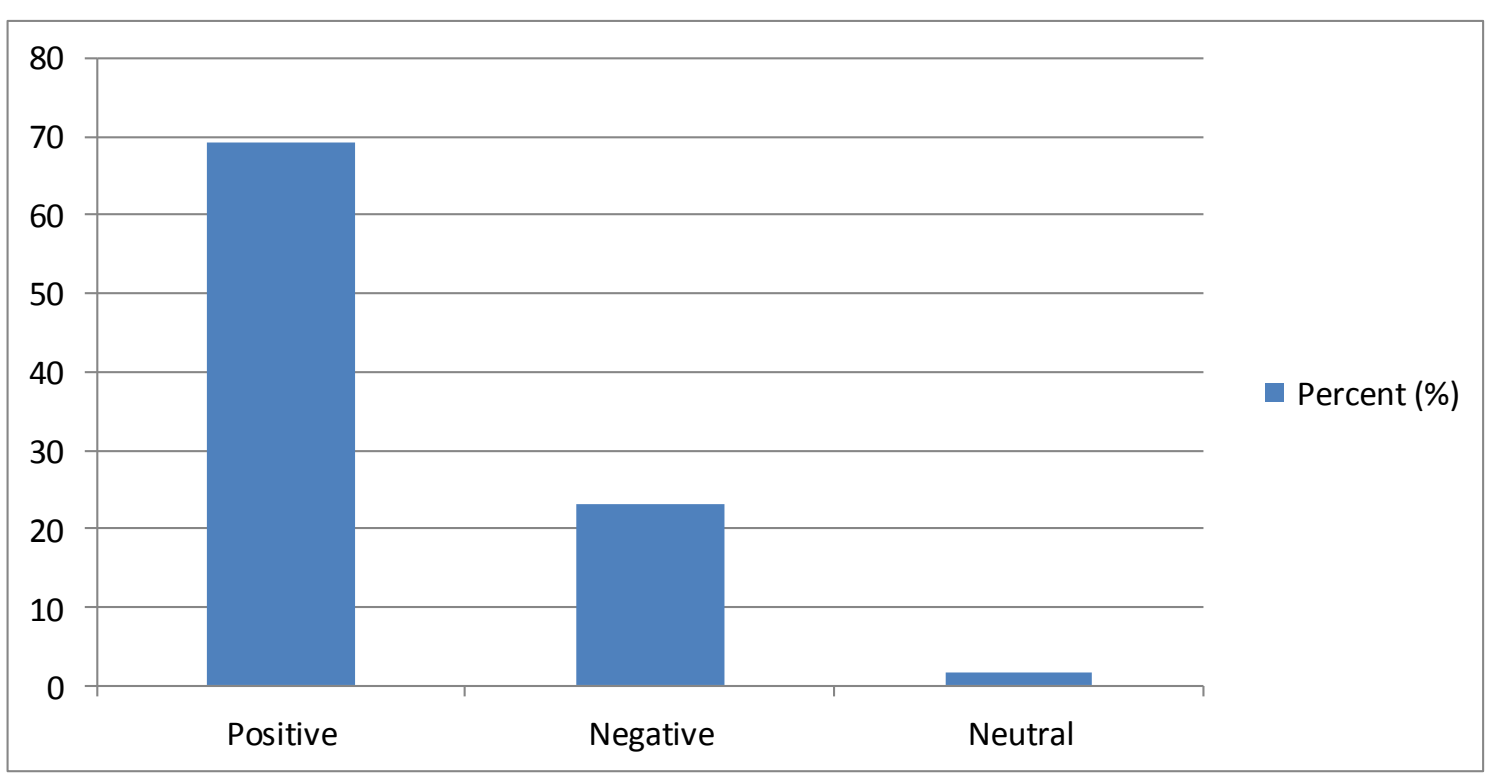

the end of the process, they were asked how their peer relations changed, and the answers were compared and analyzed separately for the pre-assessment and final assessment. Since the same dimensions were revealed in the pre-assessment and final assessment, the percentages of the dimensions were used for comparison.

Figure 1. Peer Relationships Category-Pre-Assessment

According to Figure 1, the answers about how the assessment and experience of being assessed would affect the peer relationships of the participants were divided into dimensions such as Positive (69.23\%), Negative (23.05\%) and Neutral (1.68\%). Other answers $(6.04 \%)$ were included in the group which could not be assessed in any dimension.

The dimension of Positive includes statements that the process would not damage peer relationships:

"I think I will get on well with my friends, I will make an objective assessment and get the score I deserve." (E1)

The dimension of Neutral includes answers stating that the process will not make a positive or negative change about peer relationships:

"In general, I avoid situations that will destroy my friendships." (E9)

The dimension of Negative includes answers regarding that the process will damage peer relationships:

"I think my relationship with my friends will deteriorate because there is the ambition to be successful in the class." (E10) 


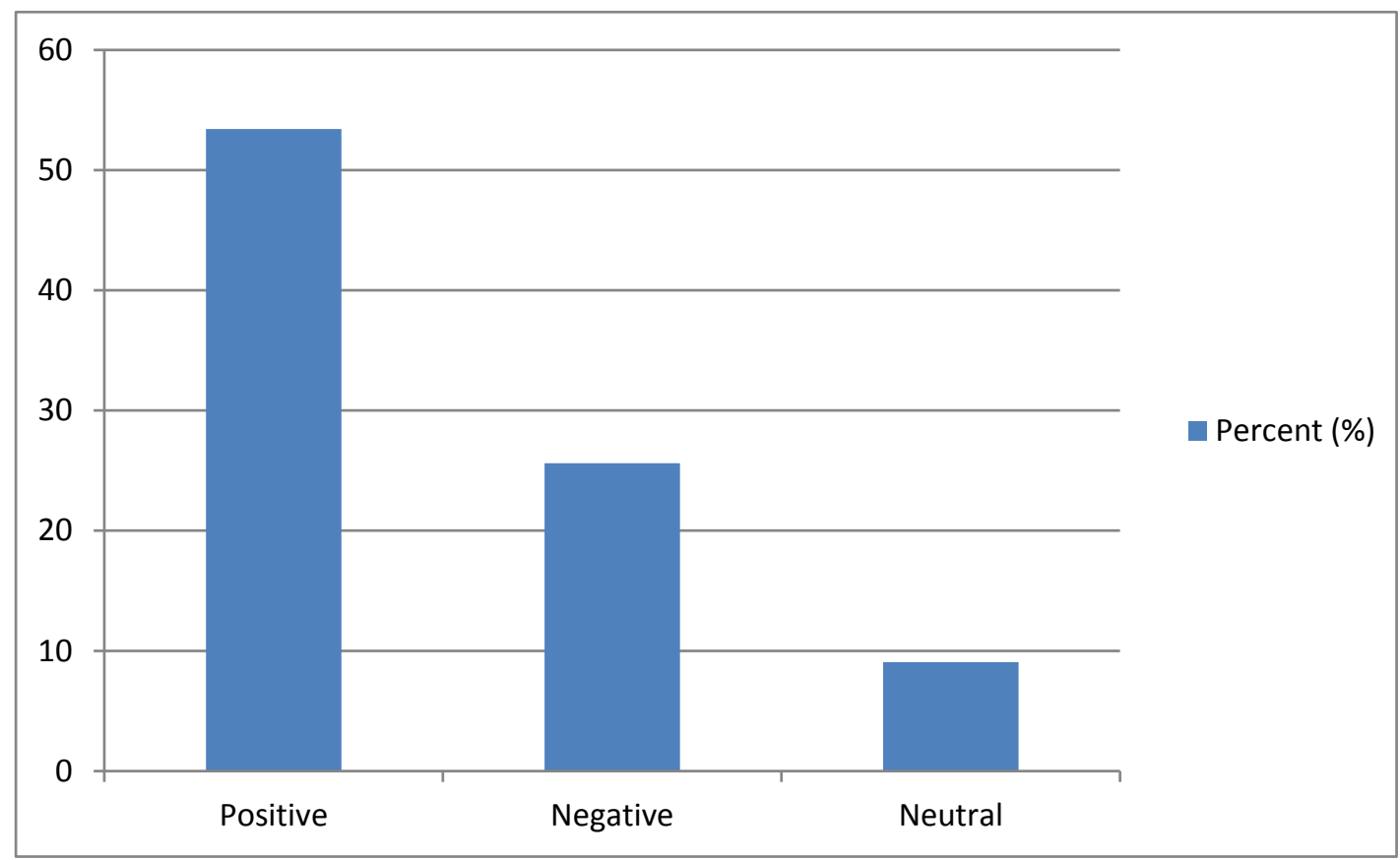

Figure 2. Peer Relationships Category-Final Assessment

According to Figure 2, the answers given to the question how the process affected their relationships with their peers are respectively positive, $(53.42 \%)$ negative $(25.61 \%)$ and neutral $(9.07 \%)$. Other statements $(11.9 \%)$ were included in the group that could not be assessed in any dimension.

The dimension of Positive includes answers regarding that the process did not damage peer relationships:

"We did not have any problem about our relationship. We behaved too fairly. We are not professional teachers; we may have deficiencies." (K1).

In addition, the students reflected on the group diary how their peer relationships were affected.

Everybody made research and shared what they found. Now, we obtained little information. We were scared but it was for nothing. Some groups were in disagreement but fortunately, we did not experience such problems (08.03.2018 Reflective Thinking Group 1 Group Diary)

The dimension of Neutral includes answers that do not involve positive or negative statements about the change which the process caused in peer relationships.

"Obviously, they do not know their grades now, everybody sees himself perfect when showing performance. However, they have a lot of deficiencies." (E2)

The dimension of Negative includes answers regarding that the process damaged peer relationships: 
"We had problems in our relationships, no matter how objective we assessed, we ignored the criticisms and compared each other." (E1)

In the reflective group diary, a participant criticized his group friend personally:

We prepared the lesson plan after great efforts. K3 did not come to the meeting and we sent him the lesson plan, he said okay without even thanking us (26.04.2018 Problem Solving Group 1 Group Diary)

When the pre-assessment and final assessment results are evaluated together, the dimension of positive determined as $69.23 \%$ in the pre-assessment decreased to $53.42 \%$ in the final assessment. However, the dimension of negative increased from $23.05 \%$ to $25.61 \%$ and the dimension of neutral increased from $1.68 \%$ to $9.07 \%$.

\section{The Effect of Being Assessed}

In this section, the answers that the participants gave to the questions directed to them such as Knowing that I will assess while teaching a lesson were analyzed and divided into dimensions. Secondly, in the last assessment, the answers are given to the question of My friends' assessing me while I am teaching a lesson... were also analyzed and divided into dimensions. Finally, the dimensions determined in the preliminary and final assessments were analyzed comparatively.

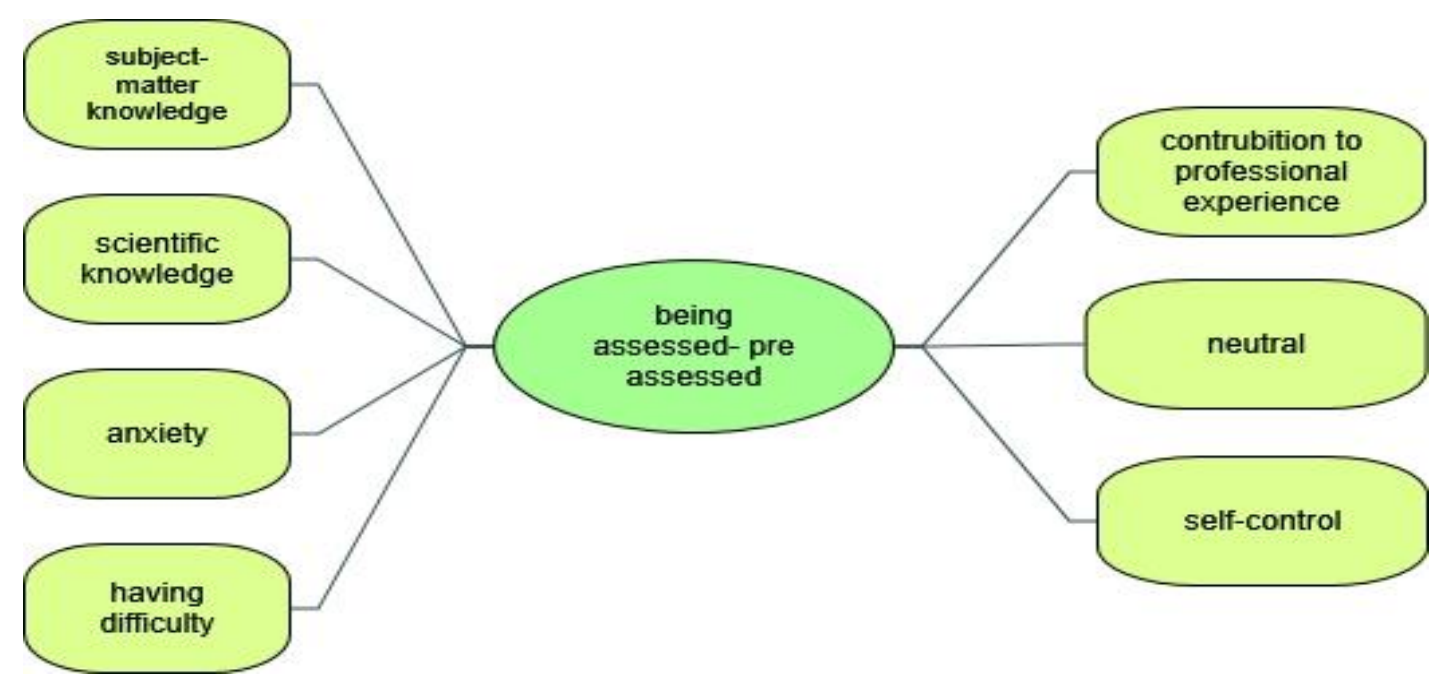

Figure 3. Being Assessed Category-Pre-Assessment

In Figure 3, the answers of the participants to the question "how do they feel to know that they will be assessed in the process" were divided into dimensions such as subjectmatter knowledge, scientific thinking, anxiety, contribution to professional experience, neutral, self-control and having difficulty.

The dimension of Subject Matter Knowledge includes answers regarding that the process will contribute to subject matter knowledge.

"We have a command of the subjects and approach objectively" (K4). 
The dimension of Scientific Thinking includes answers regarding that the process will contribute to scientific thinking skills.

"I think that I will gain speed in critical thinking and focus on the subject and flow"(K2).

The dimension of Anxiety includes answers that express concerns about the process:

"It scares me, we are not equipped."(K12)

The dimension of Contribution to Professional Experience includes answers regarding that the process will provide a professional experience.

"I will be better equipped in the teaching process; I can control my excitement." (K11)

The dimension of Neutral includes answers that do not state clearly about what kind of changes will occur in the process.

"It doesn't affect me; I can't compare myself with another." (K9)

The dimension of Self-control includes answers regarding that the process will contribute to controlling.

"It excites me, makes me do my job more attentively." (K8)

The dimension of Having Difficulty includes answers stating that the process will force them.

"I think I can have difficulties and there may be tension." (K6)

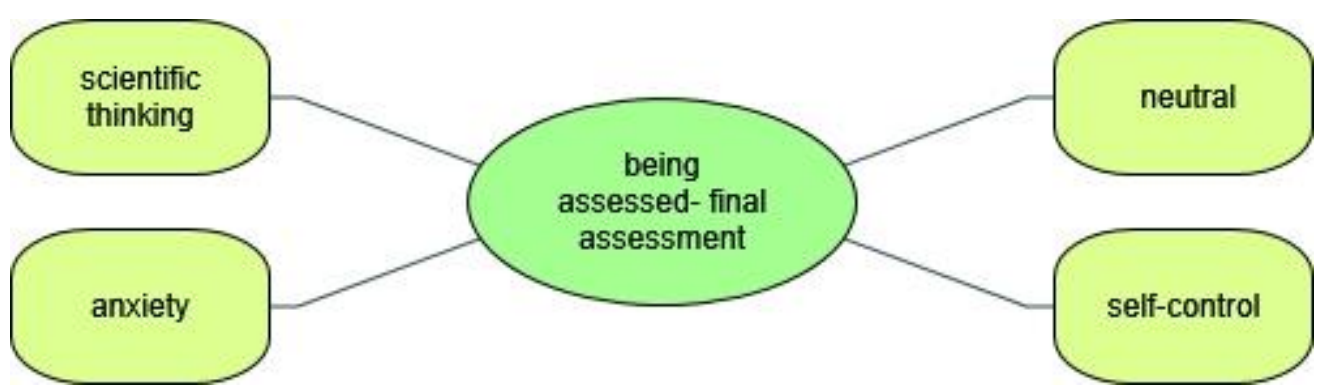

Figure 4. Being Assessed Category-Final Assessment

According to Figure 4, the changes caused by the process in the participants were divided into dimensions such as scientific thinking, anxiety, neutral and self-control.

The dimension of Scientific Thinking includes answers stating that the process increases the thinking skills of the participants. In this dimension which contains the forms of scientific thinking, K3 gave the following answer regarding reflective thinking:

"I learned what I did wrong, what was missing and what to pay attention to." 
The dimension of Anxiety includes answers regarding that the process causes various concerns:

"It disturbed me a little, everyone was trying to find a mistake..." (K10)

This dimension was also found in the reflective diaries which were kept individually. Teacher candidates shared the emotional states of their friends, who gave lessons, in their reflective diaries.

He was excited and had trouble with it. He was not prepared for the subject sufficiently because he mostly read by looking at the paper (21.03.2018 E7).

Reading by looking at the paper made me bored. This happened because of excitement (21.03.2018 K18)

He was excited, it would be better if he were a little slower. (09.05.2018 E2).

Because of being a little excited, he told quickly (09.05.2018 E1).

They also revealed the concerns of their group friends in their reflective diaries:

K19 was not very good in the presentation. He confused the places of the sentences. K12 was very excited in the presentation. He forgot some points. Apart from this, there was no problem (Empathic Thinking Group Group 1 Group Diary 03.04 2018).

The dimension of Neutral includes answers that contain statements regarding the process that did not lead to a significant change.

"There was no problem, everyone assessed each other." (K5)

The dimension of Self-control includes answers regarding that the process changed the participants' ability to control themselves.

"...It helped me to be more controlled." (K8)

Considering the pre-assessment and final assessment together, Subject Matter Knowledge, Contribution to Professional Experience and Having Difficulty dimensions determined in the pre-assessment based on the expressions of the participants were not included in the final assessment. In the reflective diaries, however, Subject Matter Knowledge is given as follows:

It would be better if he had more control over the subject. The way the subject was told needed to be more fluent. He could explain the subject a little more broadly (23.05.2018 K20).

The videos were appropriate for the purpose of the subject, the description was good. Explaining the subject with pictures was beautiful and effective. Subject matter knowledge was enough (23.05.2018, K10).

The theme of Contribution to Professional Experience which is not included in the final assessment form is supported by the reflective diaries:

The question-answer technique was used effectively (23.05.2018 K19) 
The subject was not appropriate for the class level (23.05.2018 E5)

It was nice to include a discussion in the lesson. They made defense and criticism clear on the subject to be discussed. (26.04.2018 E9).

Apart from these dimensions, Scientific Thinking, Anxiety, Neutral and Self-Control dimensions were determined as common for the pre-assessment and final assessment.

\section{The Effect on the Assessor}

In this section, the answers given by the participants, in the pre-assessment and final assessment, to the question asked to be completed as follows "For me, to assess my friends during the lesson was..." were analyzed and divided into separate dimensions. The determined dimensions were analyzed comparatively for pre-assessment and final assessment.

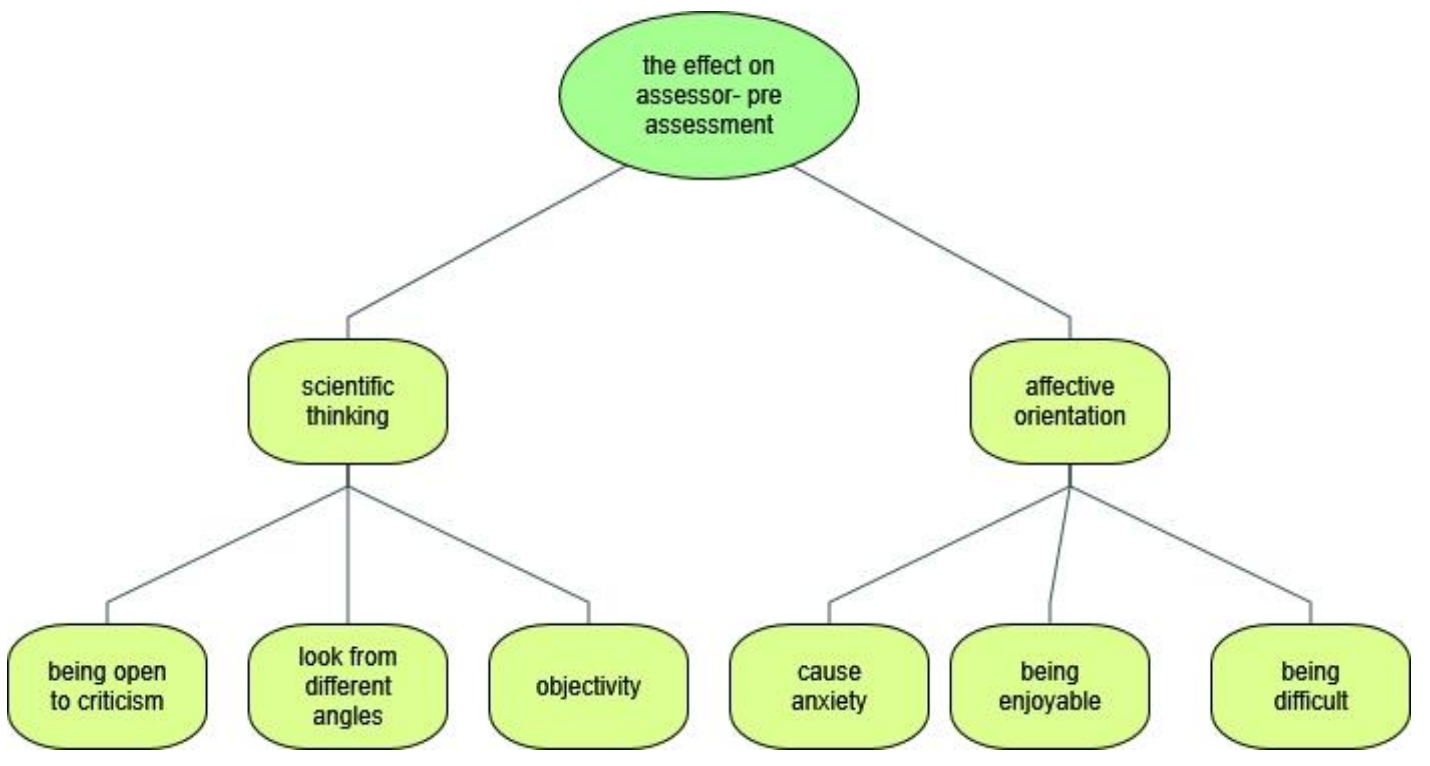

Figure 5. The Effect on Assessor-Pre-Assessment

According to Figure 5, the expectations of the participants regarding what changes will occur when the assessment is made are divided into two main dimensions as Scientific Thinking and Affective Orientation. The dimension of scientific Thinking was divided into sub-dimensions as being open to criticism, looking from different angles and objectivity; the dimension of Affective Orientation was divided into sub-dimensions as Causing Anxiety, Being Enjoyable and Being Difficult.

The dimension of Being Open to Criticism includes answers regarding that the process will make them vulnerable to criticism.

"I think it is neutral and will offer me the opportunity to compare myself". (K17)

The dimension of Looking from Different Angles includes answers regarding that the process will make them acquire the power to see events with their different aspects. 
'...My comment power and point of view about events increase." (E4)

The dimension of Objectivity includes answers regarding that the process will make them objective and free of prejudices.

"I'll be a little more objective to get rid of prejudices." (K3)

The dimension of Causing Anxiety includes answers expressing concerns about performing assessment:

"It may be a bit distressed and tense, I may not have the knowledge to evaluate objectively." (K12)

The dimension of Being Enjoyable includes answers about the feeling that the process will be enjoyable:

"Very exciting and beautiful." (E4)

The dimension of Being Difficult includes the participants' answers to the difficulties of the process.

"It can be a difficult situation that requires responsibility." (K6)

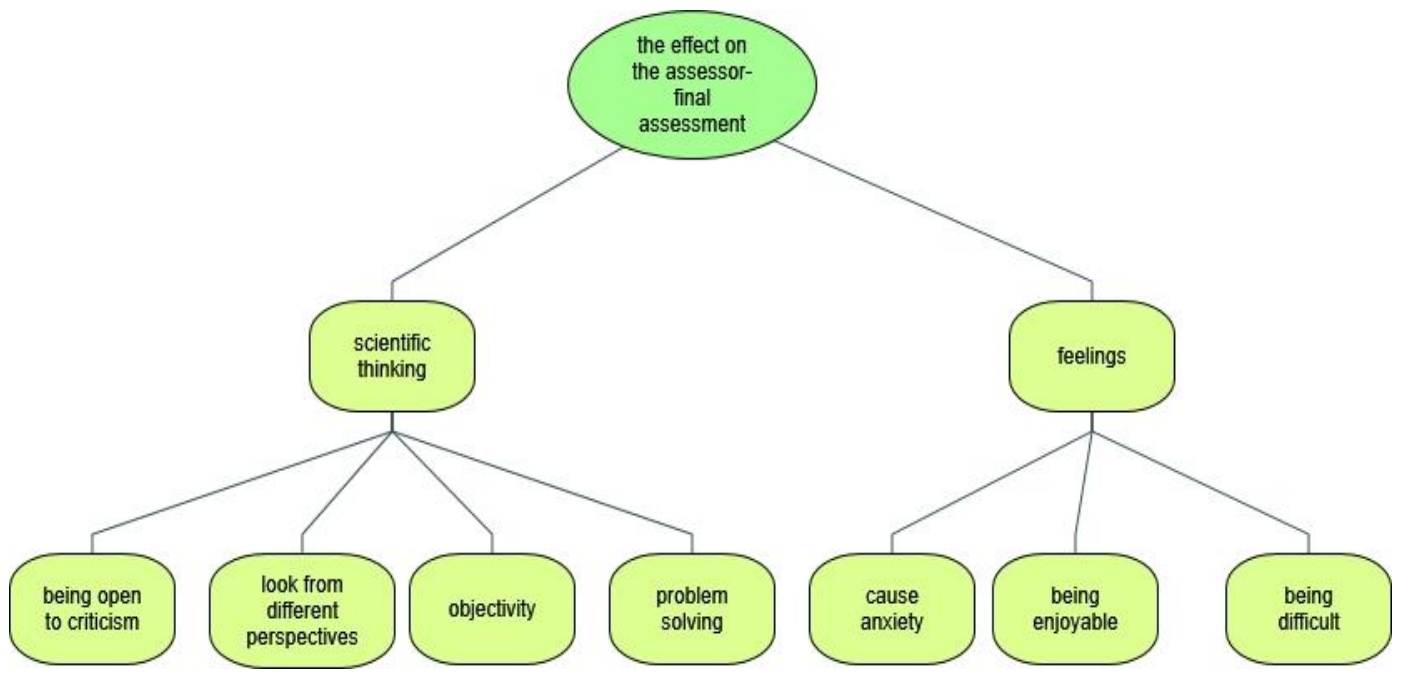

Figure 6. The Effect on the Assessor-Final Assessment

According to Figure 6, the answers of the participants regarding what changes they experienced after assessing their peers were divided into two dimensions as Scientific Thinking and Feelings. Scientific Thinking dimension was divided into sub-dimensions as being open to criticism, Looking from Different Angles, Objectivity and Problem Solving; Feelings dimension was divided into sub-dimensions as Causing Anxiety, Being Enjoyable and Being Difficult.

The dimension of Being Open to Criticism includes answers stating that the process changed them in terms of being open to criticisms.

"I realized abrasiveness about criticism." (E2) 
The dimension of Looking from Different Angles includes answers indicating that the process enabled them to see events from different aspects.

"He made me put myself in the shoes of my classmates who taught." (E6)

The dimension of Objectivity includes answers of the participants who stated that the process made them more objective.

'...I think I am fair. " (K6)

The dimension of Problem Solving includes answers stating that the process provided problem-solving skills.

"I learned to solve the problems I encountered when applying the information." (K12)

The dimension of Causing Anxiety includes answers expressing the concerns in the process.

"We were a little unsocial when assessing the lesson." (K1)

The dimension of Being Enjoyable includes answers stating that the process was enjoyable.

"It was exciting, it was a nice experience." (K10)

This dimension also emerged in the analyzed reflective diaries.

Today, we have prepared a lesson plan and the lines regarding Graham Bell's invention of the phone. It was very entertaining (21.03.2018- Reflective Thinking Group 1 Group Diary)

The dimension of Being Difficult includes the answers stating that there were difficulties in the process.

"It was a little difficult process, and I had a hard time expressing the shortcomings and positive aspects."(K11)

Considering the pre-assessment and final assessment together, Problem Solving subdimension included under the Scientific Thinking code in the pre-assessment was not included in the assessment. All remaining dimensions and sub-dimensions were found to be common for the pre-assessment and final assessment.

\section{The Effects of Active Learning Process}

This section presents the findings of what kind of changes occurred in the participants during the process. The effects of the process were classified as The Effect on Professional Knowledge and Personal Development. In each section, the dimensions determined in the pre-assessment and final assessment were analyzed comparatively. 


\section{The Effects of the Process on Personal Development}

In the category of the Effect on Personal Development, a question like "I think this lesson will change..." was asked in the pre-assessment while a question like "This lesson did not change/changed that I had" was asked in the final assessment.

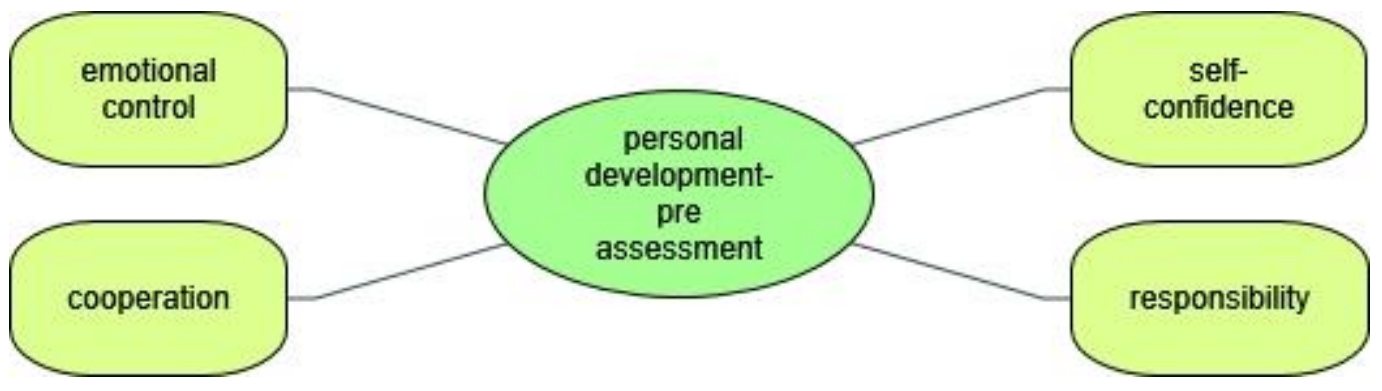

Figure 7. Personal Development Category-Pre-Assessment

According to Figure 7, the statements of the participants which express their expectations about what kinds of changes they would go through in their personal development were divided into dimensions such as Emotional Control, Cooperation, Self-Confidence and Responsibility.

The dimension of Emotional Control includes the answers given by the participants about their expectations related to managing their emotions in the process.

"...I think it might be difficult for me and there might be a tension." (K6)

The dimension of Cooperation includes the statements evaluating the process in terms of group work.

"During the lesson, I exchange ideas." (E3)

The dimension of Self-Confidence includes answers stating that the process will take the excitement factor under control and change their self-confidence:

"...It will increase my self-confidence." (E3)

The dimension of Responsibility includes answers stating that the process requires to take responsibility.

"'...There might be a situation that requires responsibility." (K6

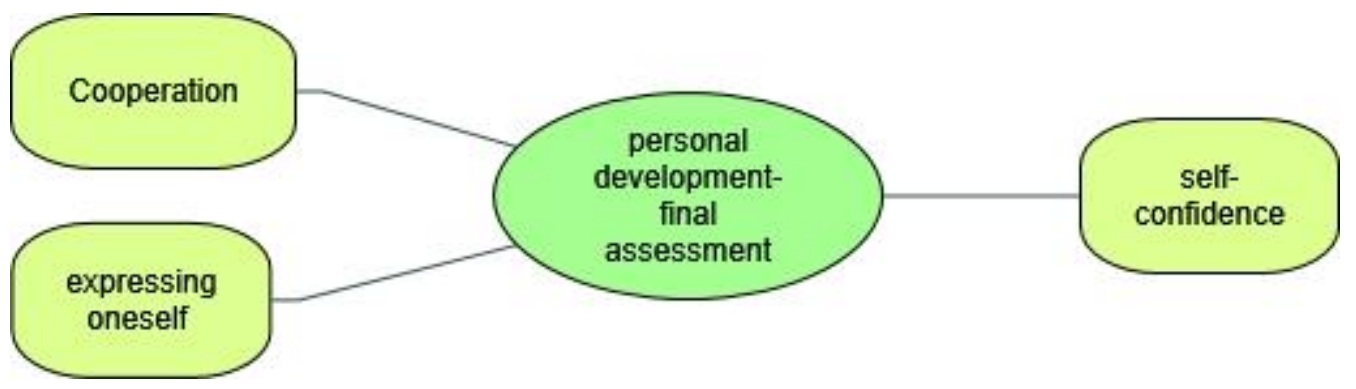

Figure 8. Personal Development Category- Final Assessment 
According to Figure 8, the answers of the participants about what kind of changes the process caused in their personal development was divided into dimensions such as Cooperation, Expressing Oneself and Self-Confidence.

The dimension of Cooperation includes answers stating that the process will make them gain the ability to work together with their peers.

"...Group work ability [Cooperation\}..." (E7)

They also stated in their reflective diaries that they could implement the cooperation theme as a contribution to their personal development:

Two of our friends prepared a lesson plan and we created a single lesson plan by mixing the two. In this way, no conflict environment occurred (10.03.2018 Emphatic Thinking Group 1 Group Diary)

E2 helped us with the division of tasks and specified his opinion. K3 told me to be careful when writing my diary and forming my sentences and I said okay (23.03. 2018 Problem Solving Group 1 Group Diary).

In the distribution of the tasks, we thought everybody needed to do something they were capable of. Since E2 was our best friend, we decided him to be the teacher (14.03.2018 Reflective Thinking 1 Group Group Diary).

We made researches about the project. We mentioned what needed to be included in the book. We looked at UN convention on the rights of children and we decided to include it in our book (30.05.2018 Problem Solving 2 Group Group Diary).

It was not easy for me to create drama content. We changed the draft suggested by K10 by exchanging ideas. We talked about the difficulty of preparing a lesson plan (06.04.2018 Reflective Thinking Group 2 Group Diary)

The dimension of Self-Expression includes answers given by the participants regarding that they went through changes in sharing their own opinions in the process.

"...Conveying my own views" (K2)

The dimension of Self-Confidence includes statements of the participants expressing that the process increased their self-confidence.

"It made me gain self-confidence." (K7)

When pre-assessment and final assessment about personal development were discussed together, it can be stated that the Cooperation and Self-Confidence dimension is common for pre-assessment and final assessment. It can be stated that the Emotional Control and Responsibility dimension determined in the pre-assessment is not included in the final assessment. In addition, the Self-Expression dimension, which is not in the pre-assessment, is included in the final assessment. 


\section{The Effects of the Process on Professional Knowledge}

In this section, the dimensions of the answers given to the questions in the preassessment such as "knowing that I will control the lesson..." and in the final assessment "to control this lesson..." were determined and presented by analyzing comparatively.

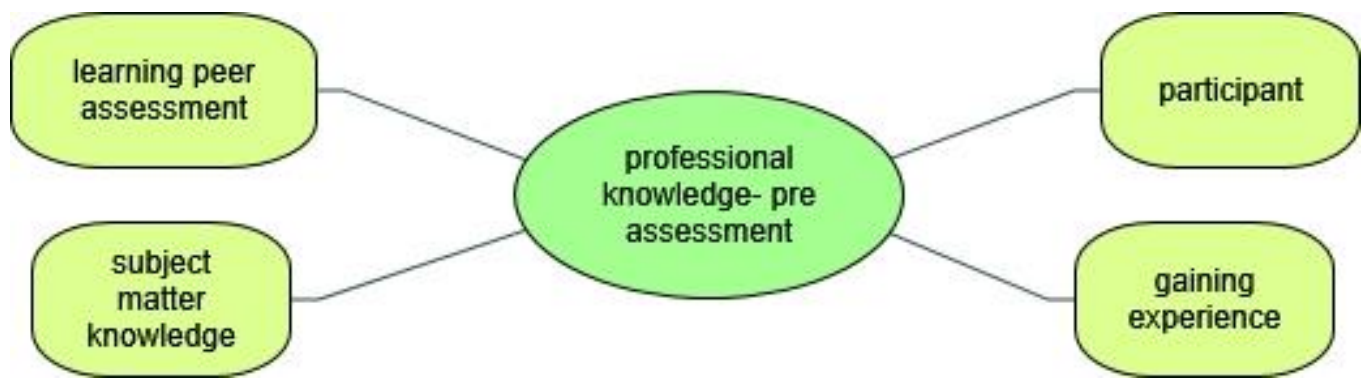

Figure 9. Professional Knowledge Category-Pre-Assessment

According to Figure 9, the expectations of the participants about the change that the process will cause in their professional knowledge were divided into dimensions such as Learning peer assessment, Subject Matter Knowledge, Participant and Gaining Experience.

The dimension of Learning Peer Assessment includes answers regarding that the process will contribute to them about learning how to evaluate their peers.

"Contribution to measurement-assessment both in the school life and in the profession." (K7)

The dimension of Subject Matter Knowledge includes answers revealing that the process changed their knowledge on their subject matters.

"It made me control the lesson and tested my knowledge." (K4)

The dimension of Participants expresses the expectations of the participants regarding that the process will change them in terms of participation.

"...I will enhance my knowledge with active participation." (E2)

The dimension of the Gaining Experience includes the answers of the participants regarding that the process will make them gain experience.

"It will be an experience for me, it will be the first step for my future teaching career to make such an assessment." (K4) 


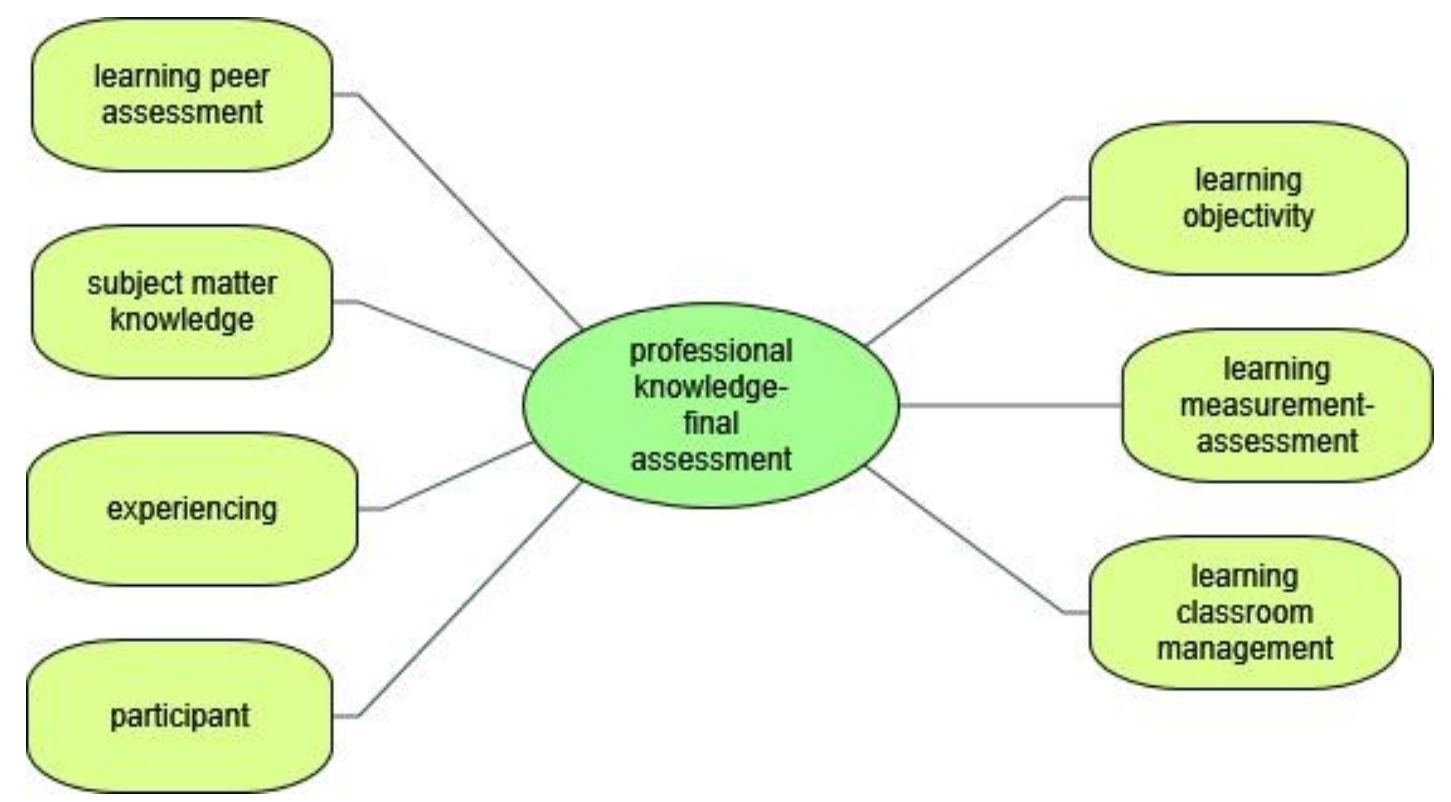

Figure 10. Professional Knowledge Category-Final Assessment

According to Figure 10, the changes led by the process in the participants' experiences about the teaching profession were divided into such dimensions as Learning Peer Assessment, Subject Matter Knowledge, Experiencing, Participant, Learning Objectivity, Learning Measurement-Assessment and Learning Classroom Management.

The dimension of Learning Peer Assessment includes answers stating that the process caused a change in the learning of assessing their peers.

"Assessing my friends increased my ability to assess." (E3)

The dimension of Subject Matter Knowledge includes answers of the participants regarding that the process changed their knowledge on social sciences.

"Preliminary Information" (K9)

The dimension of Experiencing includes the answers of the participants regarding what they gained professional experience in the process.

"It was an experience, I learned what to pay attention during the lesson." (K13)

In their reflective diaries, the students conveyed their experiences as finding the opportunity to put theory into practice:

K12 started to prepare a PowerPoint presentation. He gave importance to visuality. We paid attention to choose images with high quality and resolution (31.03.2018 Empathetic Thinking Group 1 Group Diary)

He stood in front of the class just like a teacher. He had an understandable and fluent style. The slide we watched was very meaningful. He supported the audience in 
the class to a large extent by telling almost all the rights visually. The panel presentation was good (28.03.2018 E8)

He was teaching the lesson for not only small children but also adults (05.04.2018 E10)

The dimension of Participant includes answers stating the change that the study group experienced about becoming active in the class.

"It increased my interest and participation in the class." (K14)

The dimension of the Participant was also seen in the diaries that the students kept individually. The students gave their opinion about whether their friends provided participation while teaching a lesson or not:

He awoke the attention of the students with the questions directed at the class and made the participation active (26.04.2018 E8).

It was boring when the teacher became too active, it would have been better if the student had become more active (09.05.2018 K17).

He could not attract active participation at the beginning of the lesson (09.05.2018 $\mathrm{K} 1)$

Learning Objectivity includes the answers of the participants stating that they learned to be objective in the process.

"I am not overwhelmed with my feelings anymore." (K5)

The dimension of Learning Measurement-Assessment includes the answers of the participants on the changes experienced in their knowledge about measurement and assessment:

"As a teacher candidate, I learned Measurement-Assessment." (K8)

Also, in reflective diaries, they criticized themselves and their friends about learning measurement-assessment.

In general, there was no problem with the presentation, only we made a mistake about the selection of assessment (05.04.2018 Empathetic Thinking Group 1 Group Diary).

The use of ballon as the material in the assessment was suitable for the class level but it was wrong to use a needle, also the riddles were not clear (26.04.2018 K5)

Assessment of the drama was good (03.05.2018 K1).

Learning Class Management includes answers stating the changes occurred in the class management skills of the participants.

"I learned how to control the class and communication." (K8) 
The students also assessed each other in the reflective diaries in terms of class management:

His leading in the subject was very good. His wandering between the desks enabled the participation of those sleeping behind the lesson (28.03.2018 E2).

During the discussion in which the students involved, he lost his dominance over the class from time to time, there was too much noise (28.03.2018 E5).

He walked around in order to dominate the class. It seemed that he felt he belonged to the class. For example, he turned the lights off when the slide began. He used the board actively. He was calm (23.05.2018 K5).

Considering pre-assessment and final assessment together, Learning Peer Assessment, Subject Matter Knowledge and Participant dimensions were common for pre-assessment and final assessment. The dimension of Experiencing which was determined in the pre-assessment was not included in the final assessment. Furthermore, Learning Objectivity, Learning Measurement-Assessment and Learning Class Management dimensions were included in the final assessment.

\section{The Effectiveness of Active Learning Method}

The expectations of the participants regarding what to learn from the lesson taught with Active Learning in the pre-assessment stage and the dimensions determined regarding their statements about what they learned from the lesson in the final assessment are shown in Figure 11. As seen in the figure, the statements of the participants in the pre-assessment were determined as the dimensions of Learning Peer Assessment, Scientific Thinking, Gaining Experience, Subject Matter Knowledge, Cooperation, Self-Confidence, Controlling Excitement and Participant. The answers given by the participants in the final assessment were determined as the dimensions of Problem Solving, Learning Peer Assessment, Gaining Experience, Learning Objectivity, Being Enjoyable, Self-Expression, Cooperation, Self-Confidence and Participant. The dimensions of Learning Peer Assessment, Cooperation, Self-Confidence and Gaining Experience included in the pre-assessment and the final assessment was determined as common. 


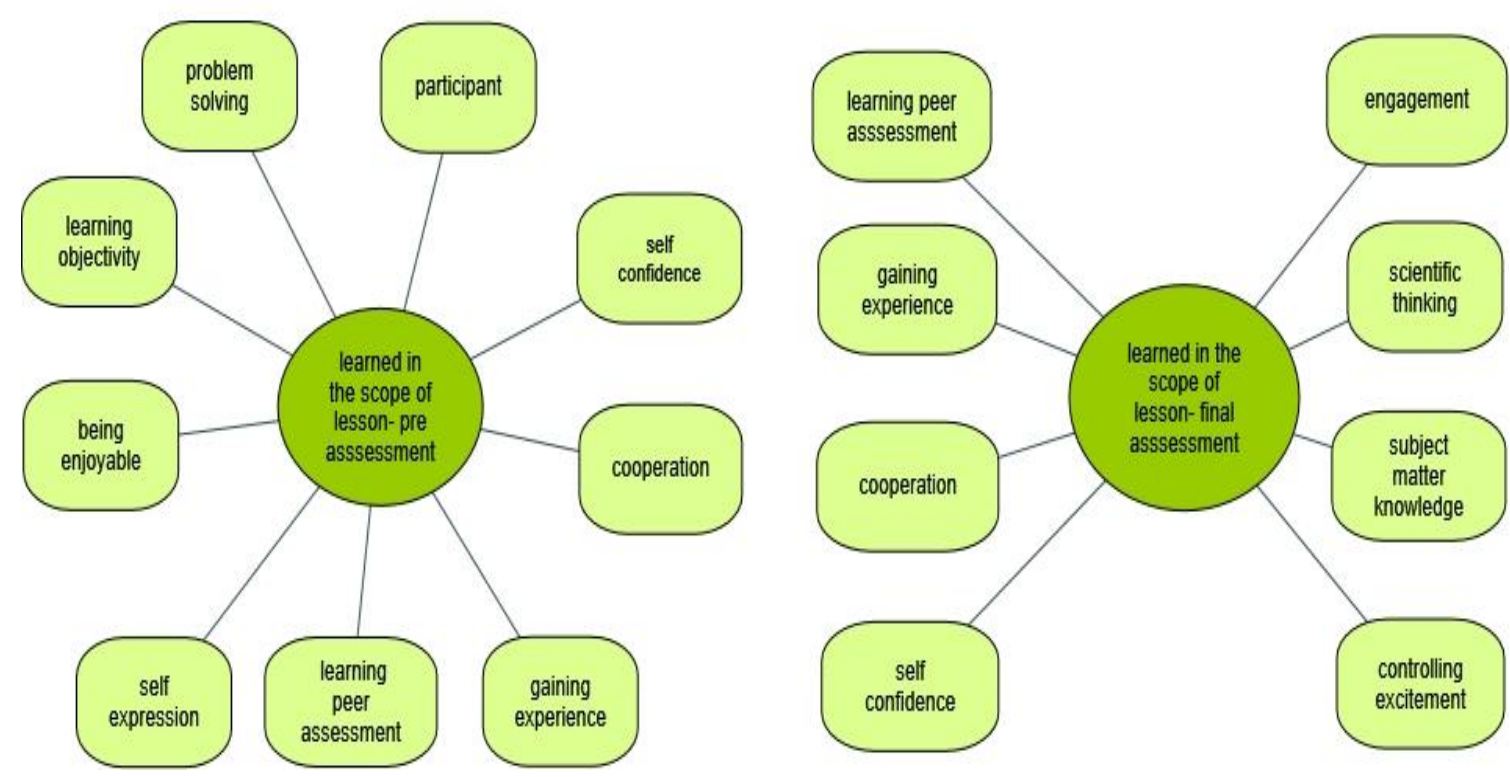

Figure 11. Pre-Assessment-Final Assessment Learned in the Scope of Lesson

\section{Discussion}

With this study, teacher candidates found the opportunity to gain experience in teaching a lesson according to students' level, developing a suitable material for the subject and using appropriate measurement-assessment tools throughout their careers. In the study, these experiences were followed with the help of the reflective diaries. Reflective implementations are accepted as important components for professional development (Marzano, Boogren, Heflebower, Kanold-Mcintyre and Pickering, 2012). Reflective diaries develop thinking skills of individuals, enable them to understand their own learning and record all of these (cited by Dixon, 2009 from Cole, Dunlap and Moon, p. 11). Ekiz (2006) argues that the reflective diaries kept by the teacher candidates during these experiences show not only their academic notes but also their personal experiences.

Following the experiences, in order to enable all teacher candidates to participate actively in the lesson, peer assessment was added in the process. Topping (1998) states that peer assessment is the assessment performed by the students at the same level assessing each other in terms of aspects such as grade, level, and value. The studies conducted on peer assessment reveal that peer assessment is the assessment of students each other with open-ended questions based on oral presentation performances as a group or individually (Topping, 1998, p. 251). Although they have various limitations, peer assessment implementations have some positive features such as motivating students, making them realize their learning as well as improving the quality of the learning processes and products (Güneş and Kılıç, 2016). Peer assessment can be perceived as a component and form of assessment. Accordingly, the aims of teachers for practicing peer assessment in the class are as follows: 
a. Helping students to test the subjects they have learned and assisting them to think critically about these subjects,

b. Helping students about which criteria to use when assessing both their own studies and the studies of the other students,

c. Enabling students to use the criteria they have determined in order to assess the studies of their peers objectively,

d. Enabling students to work collaboratively in order to make them assess the studies of the other students with a critical perspective,

e. Obtaining feedback from the students about the studies of their peers (Temizkan, 2013: 96).

Cassidy (2006) states that peer assessment encourages the students to work harder together.

The studies conducted revealed that peer assessments had positive effects on university students. Peer assessment has positive effects for teacher candidates such as developing a positive attitude, increasing their self-confidence, enabling them to learn easily and enhancing their creativity (Kösterelioğlu et al. 2014). It is also suggested that it develops metacognitive activities (Topping, 1998; Kılıç, 2016). In this study, the teacher candidates stated that making assessments supported scientific thinking. Akpinar and Kranda (2017) stated in their study that social sciences teacher candidates expressed that peer assessment developed their critical thinking skills.

As understood from the codings in the final assessment forms, scientific thinking is discussed with different aspects in this study. Crabtree (1967) argues that the social sciences lesson is related to effective and reflective thinking and these forms of thinking can also be implemented in the classes. According to Crabtree, this implementation is related to in-class discussions and decision-making skills. In their study on the critical thinking tendency of teacher candidates, Beşoluk and Önder (2010) determined that the large majority of the teacher candidates had mild and low level of critical thinking and a small group had high level of critical thinking and noted that this result might result from the fact that the individuals were not given the opportunity that would develop their critical thinking skills in their lives. In this study, the findings related to the scientific thinking skills of the students in their active learning experience were found.

On the other hand, when the effects of the peer assessment on friendship relationships were examined, it was seen that there were also negative situations. While the students who knew each other gave higher grades in the peer assessment, the students who did not know each other or knew less gave lower grades (Özdemir \& Erdem, 2017). In line with the studies of Özdemir and Erdem, also in this study, some students stated in their reflective diaries and final assessment form that after the activity they were estranged from their friends and that there were injustices in the assessment. 
Another important issue about peer assessment is related to the concern regarding whether it is reliable or not. In the assessments conducted, according to Güneş and Kiliç (2016) the reliable scoring system is the scoring system performed by the lecturers. In their study, they concluded that the students gave higher scores to each other compared to the scores given by the lecturers. In addition, Uyar, Demir, and Aksekioğlu (2016) concluded that university students could not be objective in the peer assessment. Tropping (2018) stated that peer assessment was more reliable than self-assessment (Tropping, 2018; De Grez, Valcke Roozen, 2012). Özdemir and Erdem (2017) stated that since university students in Turkey did not encounter with a constructivist approach beginning from the primary school level, they thought that peer assessment was not conducted to provide a process-oriented active learning environment and they criticized each other but gave high scores. A similar situation was also found in this study. They wrote in the participant diaries and assessment forms that they were hesitant to make assessments.

In this study, the students performing peer assessment stated in-pre assessment and final assessment that they were worried, and it was difficult to make an assessment. According to Topping (1998), peer assessment is a process that makes a contribution but also raises concern.

In this study, teacher candidates stated that they applied professional knowledge lessons they learned in theory also in practice, and they gained professional experience in this way thanks to peer assessment. In this study, this experience can be mentioned for both active learning activities and peer assessment. Hence, the students wrote it down in their reflective diaries. Kösterelioğlu et al. (2014) revealed in their study that activity-based learning contributed to the professional development of teacher candidates.

In the 21st-century information society, the need for teaching methods based on students is an undeniable truth. With the discovery of the constructivist models, active learning models started to be used. Discussing and determining the roles of teachers and students in the process are important in terms of forming a scientific balance in the student-based teaching approach. In this case, we can say that active learning encourages scientific and creative thinking. The studies conducted reveal that active learning not only increases the accumulation of knowledge but also encourages scientific thinking (Phillips, 2005). Aydede and Kesercioğlu (2010) revealed in their study conducted at the primary school level that active learning implementations had a positive effect on the critical thinking skills of students. Also, in this study, teacher candidates expressed that the active learning process increased their scientific thinking skills. Ünveren Kapanadze (2018) revealed that in the learning environments where the students participate in the lesson actively and take learning responsibilities instead of having direct access to the information, the students' motivation, curiosity and beliefs regarding that they can achieve increased, permanent learning occurred and achievement increased. 
In this study, the changes resulting from active teaching in the student were discussed. For this purpose, the professional and personal development of the teacher candidates was emphasized. The studies conducted with teacher candidates show that scientific thinking increases self-confidence. In addition, Gümüşok (2014) determined that the implementations of peer assessment were positively reflected on students' reflective thinking skills. For teacher candidates, talking in a community, expressing their thoughts directly and creating proofs for their opinions reveal their self-confidence (Akkaya, 2012). As stated in the assessment forms and reflective diaries, the presentation experiences of teacher candidates, assessing each other and working in cooperation develop their self-confidence.

\section{Results}

The results in this study can be listed in two ways as peer assessment and active learning. The results of the peer assessment are as follows:

- It was found out that the teacher candidates assessed each other in the process and this had an apparent effect on their peer relationships. When considered in general, this peer assessment created an awareness in their perspectives for each other. Although this awareness was positive, there were some disagreements among them from time to time.

- In the process of peer assessments, awareness was created in the sense of cooperation. Final assessment findings and reflective diaries indicate that the process influenced cooperation positively.

- Peer assessment increased the self-confidence levels of the teacher candidates.

- It can be stated that when their peers assessed them, awareness was created about their thinking skills and self-control.

- Awareness was also created in their thinking skills like in their perspectives while assessing and being assessed. When expressing themselves in this field, they more clearly stated that they were thinking scientifically. For instance; they said that they were open to criticism and they could solve problems.

- Assessing their peers created an awareness in the scientific thinking skills of the candidates. For example, they stated that they could look at the situations from different angles and they were more objective. Moreover, the participants were concerned about being objective when assessing their peers, they had difficulty in the process but enjoyed the process.

- The results related to active learning are as follows:

- It can be stated in this study that an active learning process affected the scientific thinking of the teacher candidates.

- According to this study, active learning of the social sciences teacher candidates affected their personal development. For example, the teacher candidates stated that 
the cooperation between them strengthened, they could express themselves more comfortably and their self-confidence increased.

Their active learning experiences also affected their professional knowledge. This study revealed that the participants had an opportunity to practice the theories they learned theoretically with active learning. For example, they stated that they learned measurement-assessment and class management. Also, it is possible to specify that their knowledge about their subject matters increased.

\section{Suggestions}

- Faculty of education lecturers can apply peer assessment method more often in their classes.

- Further researches can be conducted on the other effects of the peer assessment.

- The studies which can be conducted on active learning can show these kinds of learning to other researchers with different perspectives.

- The information about education sciences lessons (class management, assessment, learning psychology, etc.) which teacher candidates learn theoretically can be put into practice with the guidance of the lecturers of the lesson.

- Active learning activities and peer assessment implementations which will contribute to increasing the self-confidence of teacher candidates can be performed in classes in various lessons.

- The activities which will increase the scientific thinking of teacher candidates can be organized.

\section{References}

Açıkgöz, Ü. K. (2007). Aktif öğrenme. İzmir: Biliş Yayıncılık.

Akar, H. (2018). Durum Çalışması. Eğitimde nitel araştırma desenleri. (Eds. Saban, A. \& Ersoy, A.). Ankara: Anı Yayıncilık.

Akkaya, A. (2012). The opinions of teacher candidates about speech problems. Mustafa Kemal University Journal of Social Sciences Institute, 9(20), 405-420.

Akpınar, M., \& Kranda, S. (2017). View of social sciences student teachers on peer assessment. Dicle University Journal of Ziya Gökalp Faculty of Education (29), 356374. DOI: http://dx.doi.org/10.14582/DUZGEF.768

Aydede, M. N., \& Kesercioğlu, T. (2010). The effect of active learning applications on students' critical thinking skills. Dokuz Eylul University The Journal of Buca Faculty of Education, (27), 14-22.

Beşoluk, Ş., Önder, İ . (2010). Examination of prospective teachers' learning approaches, learning styles and critical thinking tendencies. Elementary Education Online, 9(2), 679693. Retrieved from http://dergipark.gov.tr/ilkonline/issue/8595/106929

Biri, H. (2014). Contribution of peer assessment method to teacher education (Master Thesis). Karadeniz Technical University Institute of Educational Sciences, Trabzon. 
Can, Ş., \& Kaymakçı, G. (2015). Pre-service teachers' critical thinking tendencies. Education Sciences, 10(2), 66-83.

Cassidy, S. (2006). Developing employability skills: Peer assessment in high education. Education-Training, 48(7), 508-517. https://doi.org/10.1108/00400910610705890

Creswell, J. W. (1998). Qualitative inquiry and research design: Choosing among five tradition. London: Sage Publication

De Grez, L., Valcke, M., \& Roozen, I. (2012). How effective are self-and peer assessment of oral presentation skills compared with teachers' assessments?. Active Learning in Higher Education, 13(2), 129-142.

Crabtree, C. (1967). Effective thinking in the social studies, supporting reflective thinking in the classroom. Fair, J. \& Shaftel, F.R. (Eds.) . National Council for the Social Studies.

Demir, M. K. (2006). Primary school teacher candidates' learning styles and social studies teaching. Eurasian Journal of Educational Research (23), 28-37.

Dixon, B. J. (2009). "A Formative experiment investigating The use of reflective video journals to 1ncrease high school Students' metacognition". A dissertation submitted to the faculty of San Diego Ztate University and the University of San Diego in partial fulfillment of the requirements for the degree doctor of education. San Diego State University. San Diego

Ekiz, D. (2006). Self-observation and peer observation: Reflective diaries of primary student teachers. Elementary Education Online, 5(1), 47-57.

Gümüssok, F. (2014). Engaging pre - service EFL teachers in the evaluation process: Self evaluation and peer evaluation as a reflective practice in the practicum. (Master Thesis) METU Faculty of Education, Ankara

Güneş, P., \& Kılıç, D. (2016). Self-, peer- and teacher-assessment through rubrics . Mehmet Akif Ersoy University Journal of Education Faculty, 1(39), 58-69.

Kalem, S., \& Fer, S. (2003). The effect of learning environment created by active learning model on learning, teaching and communication process. Educational Sciences: Theory \& Practice, 3(2). 433-461.

Korkmaz, Ö. (2009). Teachers' critical thinking tendencies and levels. Ahi Evran University Journal of Kırşehir Education Faculty, 10(1), 1-13.

Kösterelioğlu, I., Bayar, A., \& Akın Kösterelîoğlu, M. (2014). Activity-based learning process on teacher education: a case study. Electronic Turkish Studies, 9(2), 10351047.

K1lıç, D. (2016). An Examination of using self-, peer-, and teacher-assessment in higher education: a case study in teacher education. Higher Education Studies 6(1), 136-144.

Kızıltepe, Z. (2018). Nitel araştirma, yöntem, teknik ve yaklaşimlari (Eds. Seggie, F. N. \& Bayyurt, Y.) Ankara: Anı Yayınc1lık.

Miles, B., \& M., Huberman, A. M. (1994). Qualitative data analysis an expanded sourcebook. London: Sage Publication. 
Özan, S., \& Yurdabakan, İ. (2008). The effects of self and peer-assessment on basic communication skills achievement. Tıp Eğitimi Dünyası, 27(27), 27-39.

Özdemir, O., \& Erdem, D. (2017). The effect of friendships to peer assessment of presentation skills. Turkish Journal of Educational Studies, 4(1), 21-43.

Patton, M. Q. (1999). Enhancing the quality and credibility of qualitative analysis. Health services research, 34(5 Pt 2), 1189-1209.

Pehlivan, H. (2008). Etkili Öğretim İçin Öğretmen Davranışları. Ankara: Asil Yayın Dağıtım

Phillips, J. M. (2005). Strategies for active learning in online continuing education. The Journal of Continuing Education in Nursing, 36(2), 77-83.

Somervell, H (1993). Issues in assessment, enterprise and higher education: the case for self-, peer- and collaborative learning. Assessment and Evaluation in Higher Education, 18(3), 221-233.

Temizkan, M. (2013). The effect of peer assessment on the development of speaking skill. Mustafa Kemal University Journal of Social Sciences Institute, 6(12), 90-113.

Topping, J. K. (1998). Peer assessment between students in colleges and universities. Review of educational Research, 68(3), 249-276.

Topping, J. K. (2009). Peer Assessment. Theory Into Practice, 48(1), 20-27.

Uyar, Ş. Demir, K., \& Aksekioğlu, B. (2016). A triplet on performance-based assessment: self, peer and rater assessments. International Journal of Turkish Education Sciences, (7), 69-80.

Ünveren Kapanadze, D. (2018) The effect of using discourse analysis method on improving cognitive and affective skills in language and literature teaching. European Journal of Education Studies, 4(5), 92-107.

Wagner, T. (2008). The global achievement gap: Why even our best schools don't teach the new survival skills our children need - and what we can do about it. New York, NY: Basic Books.

Yaman S. \& Yalçın N. (2004). The effect of problem-based learning approach on creative thinking skills in science teaching. Elementary Education Online, 4(1), 42-52.

Yetim, A. A., \& Göktaş, Z. (2004). Teacher's occupational and personal qualifications. Kastamonu University Kastamonu Education Journal, 12(2), 541-550.

\section{Biographical Statements}

İrem NAMLI ALTINTAŞ is an assistant professor at Suleyman Demirel University. Her areas of interest include active citizenship education.

Hüseyin KARAASLAN is a research assistant at Süleyman Demirel University. His areas of interest include financial literacy education. 